\title{
Systems Cell: a Testable Model for Systems Holism
}

\author{
A.K. Mukhopadhyay ${ }^{1}$ \\ 1 Department of Laboratory Medicine, All India \\ Institute of Medical Sciences.
}

\section{Contact information:}

\section{A. K. Mukhopadhyay}

$\equiv$ mukhoak1953@gmail.com
The equations of physical world are bereft of causality. On the other hand, the relational matrix between two or more organelles or organisms is inclusively causal because of operational presence of consciousness and other potent factors like 'life', self, mind and information within the system. Standing on the computational platform of informational molecules of systems biology what is that decisionmaking ware which makes cell's response solution-centric as well as holographic? Embedded within what is observable, measurable and reducible into parts, this paper tries to answer this question and develops how the causal operations of information, mind, self, life and consciousness connect signature informational molecules with wisdom of cellular consciousness. The entire relationship has been presented as multilayered and hierarchically nested labyrinthine ware. Systems cell can be used as a model of systems holism and be tested with the credible data from molecular mapping and multidimensional live cell image analysis.

\section{Introduction}

Cell is a living dynamic system, which is complex, not chaotic nor random. There is order and coherence in the molecular dynamics of cell as evidenced from molecular mapping and multidimensional live-cell image analysis. Cell also has a symmetry-retaining, symmetry-breaking and symmetry-making dynamics, which connects the recordable molecular dynamics with the complexity of its decision-making matrix. The property like intelligence, choice, wakefulness, symmetry-sensing and symmetry-alteration by creation of new information, in addition to cognition, emotion, will and wisdom, emerge from the decisionmaking matrix of the cell. The complexity is created by astronomical bits of information cell handles as a hologram of nature-consciousness. The cell responds holographically for a solution towards 
its commitment. It responds as a whole and it is solution-centric. The systems biology (epigenomegenome-proteome-metabolome-metalome) offers only the tip of the iceberg. The main chunk of ice remains in the submerged non-observable plane. The phenomenon in "supramolecular chemistry" of Lehn Jean-Marie [1] in the context of killing of a cancer cell by natural killer cell takes the cell dynamics to some not-clearly-identifiable operations beyond conventional molecular chemistry. Naturally, question arises could science spell those out in a cell? Is there any intangible decision-making ware distributed inside cell that contains not merely binary information, the digital reality as in algorithm of ordinary 'software', but the operations of mind, self, life and consciousness as well! Through a review of the emergent phenomena within a cell and their molecular signatures, this paper suggests cell has such decision-making ware which is multilayered and hierarchically nested, appears as labyrinth consisting of definable operations, guided by information, signals and often noise and in the process develops a model of behavioral cell-dynamics rooted in consciousness extending from the computational platform of informational molecules operating in systems biology.

\section{Scanning of phenomena for decision-making hierarchy in Cell}

Distinction between signal transmission and information transfer in cell biology is not easy. No one invokes information in signal transmission through synapses in autonomic or somatic ganglia. Information processing requires more subtlety than signal transmission as seen in cerebral cortex where each neuron is surrounded by seven to ten astrocytes and the synapse is tripartite (two neurons, one astrocyte). One astrocyte is said to modulate approximately two million synapses [2]. The phenomenon, which is difficult to understand at tissue or system level in biology (the human body is made up approximately $10^{12}$ to $10^{16}$ cells) would not be easier at cellular level. It seems signal works in the physical material plane, and information operates both in matter and mind. The mind or mind-like structure and process inside a cell could be identified by its behavioral property of selecting information endlessly from signals and noise. Simple phenomenon like stimulus-excitation coupling can be explained by activity of voltage-gated $\mathrm{Na}^{+}-\mathrm{K}^{+}$ion channel. However, biochemical-mechanical coupling like excitation-contraction coupling appears more complex, cannot be explained merely by $\mathrm{Ca}^{++}$ion channel activity as a mind-less event for a cell when the operation in the ware under discussion could modulate its gating mechanism as evident, so far, in a larger scale of behavior analysis of an unconscious patient who retains sphincter control (does not pass urine stool involuntarily in bed) till such time his mind continues to operate in that state.

Molecules working within or on the cell could be categorized into three broad groups; definitively informational ('agent' in business language) like DNA, RNA, enzymes etc., definitively non-informational, ('non-agent', 'non-client' in business language) such as water soluble excretory molecules like creatine, creatinine, urea, uric acid and so on, and those which carry information only about their self-identity to be recognized by corresponding informational molecules (client-agent relationship in business language), for example, glucose recognized by glucose receptor, LDL-cholesterol recognized by $L D L$ receptor and so on. For a non-informational molecule to become informational it necessitates conformational or configurational change such as folding, clustering, ensembling, lattice formation or polymerization, or dilution of the solvent etc. Information is sensitive to appropriateness of its vehicle, both matter and mind.

Informational molecules in the organism have a network amongst themselves, which sometimes with human attributes is described as having "molecular talk", which if done carelessly may cost 'life' [3], and when done effectively integrates [4] 
different signal pathways. This communication network, information highway, is subtler and far more extensive (e.g., between gut cells, endocrine, immune and nervous systems) than known biochemical actions and reactions, which makes 'thinking from the gut' possible [5]. The question is what coordinates for betahydroxy butyric acid, one of three ketone bodies, to behave as signal metabolite for HDAC (histone deacetylase) regulated longevity pathway [6] or for mitochondria to act as signaling platform in talking to other organelles [7] or for protein molecule Scap to sense cholesterol concentration in the membrane of endoplasmic reticulum and transmit this information [8] to nucleus through SREBP (sterol regulatory element-binding protein) pathway? Such events cannot be reduced to as an expression of self-organization! "Self-organization is creation without a creator attending to details" [9]. That what experiences and decides is self. Cell has an uncanny sense of self that explains phenomena like self-renewal and self-assembly. Self is what distinguishes it from non-self. At the ionic level cell's self-identity is maintained by various ionpumps. At the molecular level the interest of self is looked after by protein-complex of MHC-I molecule. Whole immune system works on the basis of this distributed 'self' [10].

The self of self-organizing system, which is alive and of that, which is not alive differ. There is no choice in self-organization of a fractal, where one finds identical patterns within pattern endlessly. However, a living cell has the ability to choose. To make a choice is a behavioral property of 'self' in presence of 'life'. Wherever there is a phenomenon of choice by any organism, organelle, molecule, particle or wave, it is because of concurrent presence of 'life' in the operation! The self applies its mind on an informational problem and then makes a choice mostly on the basis of available options (not previously known, and thus differs from robot) and outcome analysis of their subsequent phenomenology. As mind is sensitive to informa- tion, so self is sensitive to phenomenon. What one observes is emergence of 'intelligence' within the system ("Bacteria are small but not stupid", James A. Shapiro, 2006, Exeter meeting; also compare the phenomenon of 'quorum sensing' by bacteria). Intelligence could be viewed as a product of interaction between self and mind, each operating with its respective memory; self with memory of episodic experience and mind with informational or semantic memory.

What is missing in non-living entity that deprives it of having any choice! What could be that intangible non-localizable stuff [11]? In articulating this, Tibor Ganti [12] has perhaps phrased it as "principles of life", western philosophers have named it élan vital and the eastern philosophers have called it life-principle. In absence of this "principle" there is no choice. Self may be different from cell to cell but "principles" of life is identical in all cells. Lifeprinciple is sensitive to symmetry and the choice concurs accordingly. Sensing symmetry, retaining breaking and re-making symmetry by creation of new information is property of life-principle. Could there be any molecular signature of this principle? This is yet to be identified. Pressure-gated (cytoskeleton-gated) ion channel appears to be a strong candidate since detachment of cytoskeleton from cell membrane is either for cell division (a new 'life') or for apoptosis (end of 'life'). DNA-translation to protein is a downstream operation of 'life'. A segment of DNA can translate only when it is inside a living cell! Cell division is one of the conditions when symmetry-sensing, -breaking and -remaking are in full display, complete molecular signatures of which is yet to be identified as concluded in a recent review on organelle dynamics during mitosis [13].

Chaperonins (engaged in protein folding), Myosins (responsible for directed sliding movement), Kinesins and Dynenins (cargo transport), ATP synthases (unidirectional rotational movement) and bacterial flagella proteins (flagellation) are exam- 
ples of intelligent molecular machines within a live cell. From the examples cited emerges Biologically Inspired Systems Science (BISS) for artificial molecular devices, lab-on-chip and nano-robot which, although robustly programmed, are tiny fragments of the whole, have few options and without any choice [14].

Moreover, a choice cannot be made if the cell is not awake! It is unlikely that a sleepy cell makes a choice. It is also doubtful whether self and lifeprinciple combine can keep the cell awake abreast with developing situation amidst incessant informational or phenomenal inputs! What keeps cell wake? Isn't true that wakefulness is always described in reference to some ground (see below)? Quality of choice depends on degree of awakened state.

We draw a full circle with the fact that the only source of any new information is 'life'. A non-living entity can store or transmit information but cannot generate new information. Even inside a living eukaryotic cell the ultra-structure of microtubules is conducive for storage of information, as in DNA it is conducive for heritable transmission! Storage of information in living cell is carbon-based while in matter it is silicon-based. Algorithmic program is in the genetic code from means to end. DNA produces proteins of microtubules and the cytoskeleton-gated ion channel in cell membrane, in turn, regulates information flow. From cell membrane to microtubules to DNA and vice versa, therefore, is a direct channel for flow of information. Evidences are accumulating (http://www.fosar-bludorf.com) for hyper-communication by information stored in DNA which while within living cell (not in vitro) often behaves like magnetized wormholes (in larger scale Einstein-Rosen bridges in the vicinity of black holes) when in certain specific conformity. Information is measurable in terms of uncertainty reduction and its effect is observable when it is working with matter. Information has two more aspects; content aspect, which is deciphered by mind or mind-like structure and process inside the cell and the intent aspect, responsible for information's potent causal effect, which is connected with self's operation. Information thus, when active, looks like a trifoliate leaf connecting matter mind and self. Its measurable folium operates with matter, its content-folium operates with mind and the intent-folium operates with self. [15]

From information to mind to self to life to information is a complete circle! The answer to the question where one is sure to get a tiger's head is, "four feet in front of its tail!" Even in describing circularity, one needs a reference point or a ground, which in this case is the tiger itself. In the context of information, mind, self and life, the reference ground could be what we have been calling cellular consciousness. To be brutally honest, the buck stops here. Joint operation of self and life keeps the organism awake only with the operational consent of this ground (nearby molecular footprints: mutated prion protein in Familial Fatal Insomnia [16]). As an overarching ground, consciousness looks after and integrates what all are going on autonomously in mind, self and life of the cell, which otherwise will go chaotic. The evidence so far is in larger scale; an unconscious patient where consciousness is non-functional within the system, his mind continues to work with information, he is alive and even his self-sense is functional. However, nothing is there to hold the operations together to produce a unified behavior! Consciousness also restricts a situation of multiple divided 'self'. Besides, unlike any other ground consciousness is a participating ground, the presence of which is behaviorally recognized by cognition, emotion and will. Every cell is a cognitive unit of life rooted at the molecular level in form of receptors like NMDA (N-methylD-aspartate), events such as kinase activation and phosphatase regulation, and in activity of downstream array of transcription factors like CREB (CAMP response element-binding protein). There are a lot of "thoughts" before the genes jump! "Jumping 
genes have essential biological functions" (Science Daily, Feb [19], 2015). That cell expresses emotion is evident from phenomenon of "frustrated" phagocytosis [17] followed by release of destructive enzymes form ego-organelle lysozome and in the effects of 'bliss molecule' endorphin or 'love molecule' oxytocin! Development of stress-induced anxiety results from intracellular cascade collapsing endocannabinoid signaling in amygdala of brain [18]. While self makes choice out of available options, consciousness expresses 'will' through 'self'. The last laugh in shutting down the living state by initiating apoptosis, (molecular signature: Fasreceptor, PD receptor for ligand-1 and -2 , caspase pathway), or passage to immortality as cancer cell having survival opportunism by increasing the telomere length (molecular signature: telomerase) or making more quadruplex DNA [19] is suggested to be based on this 'will' of cellular consciousness! When consciousness decides, it takes all stakeholders like mind, self, life, and information on board. Consciousness is tough to negotiate. It responds only to merger of properties in it. Involvement of consciousness with nature makes cell's response holographic.

Cellular decision-making matrix thus is hierarchically nested spiraling from matter to informa- tion, mind, self, 'life' and consciousness. Scrutiny of signals by mind helps in selecting meaningful data as information. Phenomenological analysis of information by self makes this a formative knowledge, which has space and time constrain of the system. When successfully verified through filters of life-situations, formative knowledge transcends conditioning culture media and becomes transformative knowledge. When intentionalthreshold of information, concern-threshold of self and perfection-threshold of consciousness concur, the knowledge is affirmed as 'wisdom' of the cell, which is conferred autonomy within holonomy of systems cell, reflected as a great political statement of consciousness, distributed evenly downstream to the informational molecules, which makes cell's response holographic. Quantum physicists propose quantum entanglement and quantum holograph in nature, however the cell having operations of mind, self, life and consciousness is a model where one can demonstrate information entanglement and communication of wisdom through information holograph.

Sensitivity of identified operations and their probable molecular signatures are summarized in Table 1.

Table 1. Decision-making operations/operators, their sensitivity and probable molecular signatures.

\begin{tabular}{|c|c|c|}
\hline $\begin{array}{c}\text { Decision-making } \\
\text { Operators/ } \\
\text { Operation }\end{array}$ & Sensitive to & Probable Molecular signatures \\
\hline Information & Appropriateness of vehicle & Informational molecules \\
\hline Mind & Information & Calcium ion channel etc. \\
\hline Self & Phenomenon & Ion-Pumps, Protein complex of MHC-I Molecules etc. \\
\hline Life-Principle & Symmetry & Pressure (cytoskeleton)-gated ion channel etc. \\
\hline Consciousness & & $(?)$ \\
\hline Cognition & Information \& Phenomenon & NMDA receptor, Kinase activator, Phosphatase regulator and CREB etc. \\
\hline Emotion & Life-situation & Oxytocin, Endorphin, Endocannabinoids and their receptors etc. \\
\hline Will & Merger of properties & $\begin{array}{l}\text { Fas-receptor, PD receptor for ligand-1 \& -2, caspages, Telomerase, } \\
\text { Quadruplex DNA, (?) Prion proteinc, etc. }\end{array}$ \\
\hline
\end{tabular}




\section{The Image of the Model}

Is it possible to draw a conceptual image out of what has been said above? Five potently causal autonomous operators or operations have been tentatively identified (it does not matter at this stage whether those are ontological entity or defined epistemological process). The operations, although not strictly localizable, have defined representation in the image of the matrix of this decision-making ware (Fig. 1). Operations are found hierarchically nested spiraling down from and leading up to consciousness. Computational platform begins on the informational molecules of systems biology. Relationships amongst different operations are one to one, circular, and triangular or intertwined. Moreover, there are inter-operation activities. All add to the complexity of resilience ("achieving positive outcome in the face of adversity") and solutioncentric decision-making process in a cell.

Circularity described earlier is beneath i.e., excluding consciousness. Circularity also closes a model. The 'exit' button to get out of circularity is at the hands of 'self', but commanding authority is consciousness. All circularity, including that of 'self' and 'life' ends in consciousness.

Mind's operation is at the center of the image, connected straight to consciousness at the deepest recess and to informational molecules at the computational platform of systems biology. Consciousness-mind-matter forms the central axis of this relationship. Mind bereft of consciousness is nonproductive and is perhaps sterile. Fecundity of mind can thus be accounted by its connection with consciousness while infidelity can be explained on the basis of mind's association with matter.

In the superficial layer of the matrix, information, mind and life maintain a circular or triangular or intertwined relationship. Life is the source of new information. Mind handles all information, new or old. Information helps in adaptation of life to a new situation. Many decisions come out from this triplehelix of nature. Another similar circular or triangular decision-making relationship is observed amongst self, experience (memory) and mind. The outcome is intelligence. At a deeper level, self and life maintain another triangular relationship with the ground consciousness to keep the organism awake and make choice.

Interestingly, several other hidden triangles could be identified in this matrix of relationship. Information memory and matter form the triangle at the bottom, harnessed in computer science. Information memory and consciousness form the largest triangle, which many of us recognize as an issue in consciousness study but do not know what to do with it or how to go about it! Mind self and life form the central triangle, fed from deeper recess by consciousness, from environment by information and from inside by memory and experience. The outcome is externalized through mind.

Many mathematicians (e.g., Alvin Swimmer in email group communication with author) can draw a spiral out of several triangles appropriately located. The spiral produces a sense of levels when viewed from side. The point of origin of such spiral in this context remains consciousness (compare the philosophy of Pointillism).

Besides the straight lines in the triangles, there are several straight, one-to-one, connections in this model such as consciousness-mind-matter axis. The matter is also connected straight to information (the right base of the figure). This relationship through mind-like device is harnessed in computer programming. Matter is also connected straight (left base of the figure) to experience of self. This relationship is harnessed in creating artificial intelligence. The intelligence of a robot is non-intuitive. Intuitive, nonalgorithmic intelligence to originate requires presence of 'life'.

\section{Testability of the Model}

The model proposed is of decision-making celldynamics rooted in consciousness and is also of consciousness-behavior labyrinth rooted in molecu- 
Figure 1: Systems Labyrinth of Cellular Consciousness embedded in Systems Biology.

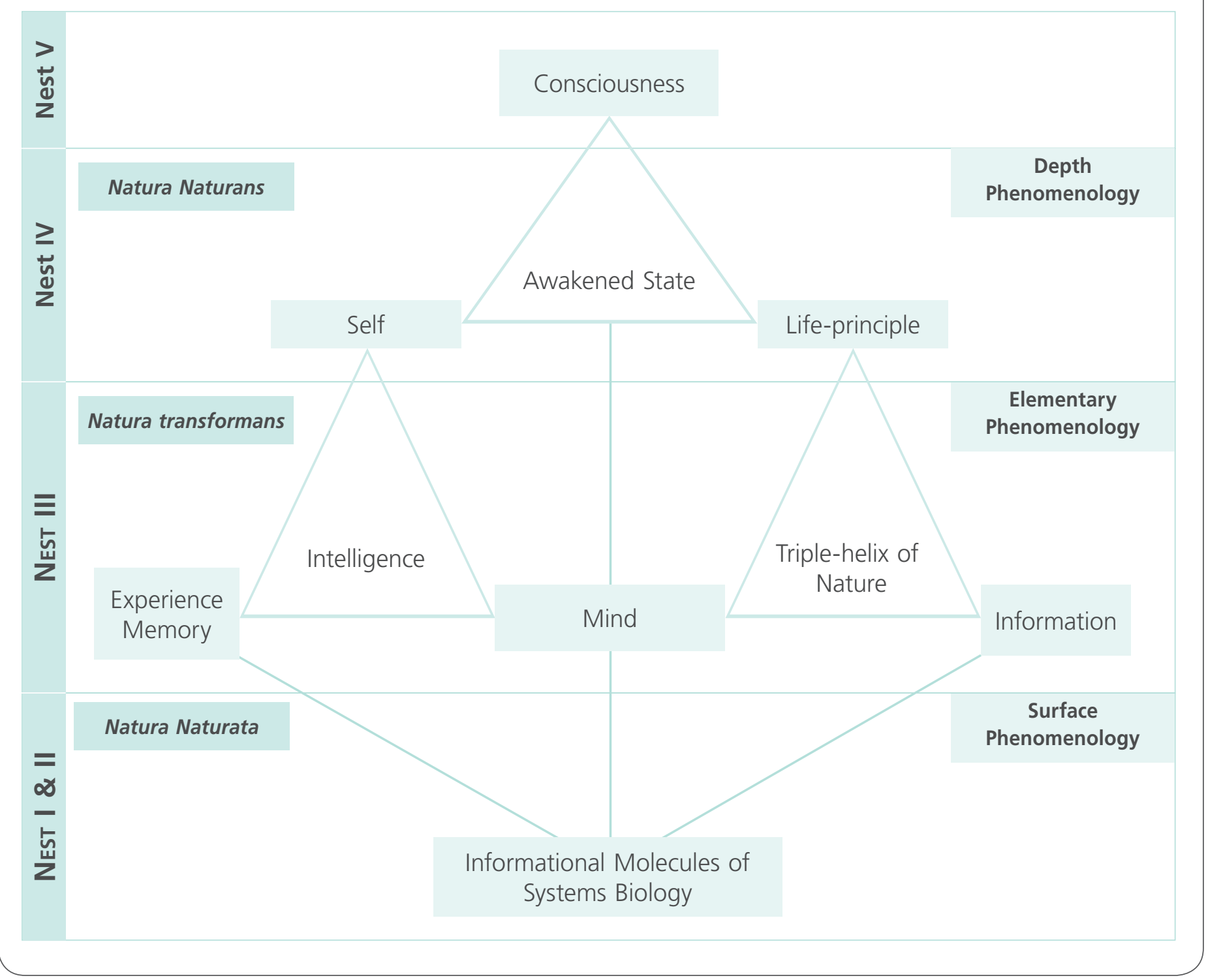

les within a cell. In both ways it is embedded with systems biology. Because of lack of technology, it is difficult at this stage to identify the operations or their operators objectively in this multi-layered ware. However, behavioral analysis of a living cell could be done by available technology like confocal microscopy, lattice light-sheet microscopy (e.g. photoactivated localization microscopy, PALM), multidimensional live cell imaging and molecular mapping by optical nanosensor technology. It would not be impossible to connect this objective data on cell dynamics precisely with the specific operators/ope- rations involved and thus to connect the systems biology with systems psychology of cell.

\section{Discussion}

This model is neither a monoplane nor a monolith. The decision-making ware is multi-layered, hierarchically nested and showing spiraling from and to consciousness. Bottom up and top down concurrence constitutes its integrity. Spinoza (Democratic Underground.com) divided nature into natura naturans, the creative nature (self-causing activity) 
and natura naturata, the created nature, "nature natured", a passive product of an infinite causal chain. The author suggests that there is a transition between the two. This nature under transition may be called natura transformans. In this nested hierarchical arrangement, five nests could be identified from surface to deep, one embedded within the other. On the surface there is nature amenable to classical physics (nest I) embedded within nature amenable to quantum physics (nest II) [both belong to natura naturata], which in turn is embedded within the nature from where 'information', 'intelligence', 'memory' and 'mind' operate (nest III) [natura transformans] and deeper, the nature from where 'life' and 'self' operate (nest IV) [natura naturans]. Finally, in the deepest nest there is the ground, the nest of consciousness (nest V) within which four superficial nests are embedded. All of the nature works on the foreground of consciousness. Thus we get a 'Five in One' or Pentaune model of nature-consciousness (compare, Pancha kosha model of human body in Taittiriya Upanishad). The unfolding described may also be visualized as explication, to some extent, of David Bohm's "implicate order" or "generative order"! Bohm's ever-implicate order will remain as consciousness itself. What has been made explicate in this concept paper are those downstream of consciousness. Information directly cannot reach and connect with consciousness. In between there is mind, memory, self and life, all of which make the decision-making matrix multilayered and hierarchically nested. The model also offers a new phenomenological approach to the issue of consciousness. Self handles phenomenology. While surface phenomenology belongs to material world and depth phenomenology to self and life, the elementary phenomenology is sandwiched between surface and depth phenomenology with operation of intelligence, memory/experience, mind and information. Systems Holism, originally proposed by Jan Christian Smuts (1870-1950) is limited by its boundary problem and suffers from the lack of adequate vertical depth. Such problem has been reasonably overcome in consciousness-behavior labyrinth of a living system by identifiable operations of self, mind and consciousness. Accurate and detail identification of molecular signature of these operations and their interrelationship remains the cornerstone for verification of this model.

\section{Perspectives}

Applicability of the model for programming in synthetic biology with digital simulation (a great scope for digital industrialist), and its implications in molecular gateway to psyche (a grand scope for psychiatric drug manufacturer), and its utility in selfmanagement, information-management and human resource management or in extending science beyond "nature natured" are open to further investigation. Kotas and Medzhitov [20] have recently described the phenomenon of homeostasis from systems engineering perspectives. The present article, by expanding Claude Bernard's original concept of milieu interieur up to the depth of consciousness, redefines the scope of Walter Cannon's concept of homeostasis and Curt Richter's inclusion of behaviorism [21] in the concept of health and disease. Further, in the big picture of consciousness research, what is the real gap in different existing theories, which have been trying to explain consciousness? This is the explanatory gap existing between information and consciousness! Filling up this 'Grand Canyon' between information and consciousness requires a huge effort! Multilayered hierarchically nested labyrinthine decision-making ware of consciousness could be this missing link in developing a science for consciousness. The model also offers a comprehensive image of the psyche, which consists of operations of consciousness, self, life, mind and information. Psyche has been redefined as poIylithic; its structure, operation and molecular links have been suggested in this model. 


\section{Concluding Remarks}

The essay raises three important questions. First, is the proposition simultaneously simple and general? Thorngate's postulate of commensurate complexity, also called impostulate of theoretical simplicity, states, "In order to increase both generality and accuracy, the complexity of our theories must necessarily be increased." Apparently looking simple, the proposed model has reasonable complexity when all the variables are incorporated. Second, is systems biology a virtual reality of systems psychology of mind and intellect, which in turn is a virtual reality of self, which in turn is a virtual reality of consciousness? In the process of creating such cascade of virtual (digital) reality are we not excluding "life", which forms the sine qua non of a cell and cannot be digitized! Third, is it possible to make a model of holograph inclusive of what all is known to us? Probably, the answer is Systems Cell!

\section{Acknowledgement}

Dr. Shyam Prakash, PhD, Senior scientist and Asst. Prof. in the Department has helped in editing the paper and Dr. Pooja Pallavi, PhD, author's student, has helped in referencing the manuscript.

\section{References}

1. Lehn, J-M. (2007). From supramolecular chemistry towards constitutional dynamic chemistry and adaptive chemistry, Chem. Soc. Rev. 36, 151-160.

2. Oberheim, N. A., Wang, X., Goldman, S., and Nedergaard, M. (2006). Astrocytic Complexity distinguishes the human brain. Trends Neurosci. 29, 547-553.

3. Carter, E. P., Fearon, A. E., and Grose, R. P. (2015). Careless talk costs lives: fibroblast growth factor receptor signaling and the consequences of pathway malfunction. Trends Cell Biol. 25, 221-233.

4. Creagh, E. M. (2014). Caspase crosstalk: Integration of apoptotic and innate immune signaling pathways. Trends Immunol. 35, $631-640$

5. Schmidt, C. (2015). Mental Health: Thinking from the Gut. Nature 518, S12-S15.

6. Newman, J. C., and Verdin, E. (2014). Ketone bodies as signaling metabolites. Trends Endocrin. Met. 25, 42-52.

7. Raimundo, N. (2014). Mitochondrial Pathology: Stress signals from Energy Factory. Trends Mol. Med. 20, 282-292.

8. Motamed, M., Zhang, Y., Wang, M. L., Seemann, J., Kwon, H. J., Goldstein, J. L., and Brown, M.S. (2011). Identification of luminal Loop 1 of Scap protein as the sterol sensor that maintains cholesterol homeostasis. J. Biol. Chem. 286, 18002-18012.

9. Bremermann, H. J. (1994). Self-organization in Evolution, Immune systems, Economics, Neural Nets, and Brains, In, On Self-Organization. An Interdisciplinary Search for a Unifying Principle, R. K. Mishra, D. Maa and E. Zwierlein, editors, (Berlin: Springer-Verlag), 5-34.

10. Forsdyke, D. R. (2015). Lymphocyte repertoire selection and intracellular self/non-self-discrimination: historical overview. Immunol. Cell Biol. 93, 297-304.

11. Brooks, R. (2011). The Relationship between Matter and Life. Nature 409, 409-411.

12. Gánti, T. (2003). The Principles of Life. (Oxford: Oxford University Press)

13. Jongsma, M. L. M., Berlin, I., and Neefjes, J. (2015). On the move: organelle dynamics during mitosis. Trends Cell Biol. 25, 112-124

14. Kinbara, K., and Aida, T. (2005). Towards Intelligent Molecular Machines: Directed Motions of Biological and Artificial Molecules and Assemblies. Chem. Rev. 105, 1377-1400.

15. Mukhopadhyay, A.K. (2013). Setting the Agenda for a Science of Information. Talk delivered as Invited Speaker at Twentieth Conference of Towards a Science of Consciousness (TSC 2013). (http://akmukhopadhyayconsciousness.com/pdf/ LINK14.pdf) 
16. Medori, R., Tritschler, H. J., LeBlanc, A., Villare, F., Manetto, V., Chen, H. Y., Xue, R., Leal, S., Montagna, P., Cortelli, P., et al. (1992). Fatal Familial Insomnia, A prion disease with a mutation at codon 178 of the prion protein gene. N. Eng. J. Med. 326, 444-449.

17. Liszt, F., Schnittker-Schulze, K., Stuhlsatz, H. W., and Greiling, $\mathrm{H}$. (1991). Composition of proteoglycanfragments from hyaline cartilage produced by granulocytes in a model of frustrated phagocytosis. Eur. J. Clin. Chem. Clin. Biochem. 29, 123-130.

18. Qin, Z., Zhou, X., Pandey, N. R., Vecchiarelli, H. A., Stewart, C. A., Zhang, X., Lagace, D. C., Brunel, J. M., Beique, J. -C., Stewart, A. F. R., Hill, M. N., Chen, H. -H. (2015). Chronic Stress Induces Anxiety via an Amygdalar Intracellular Cascade that Impairs Endocannabinoid Signaling. Neuron 85, 1319-1331.

19. Balasubramanian, S., Hurley, L. H., and Neidle, S. (2011). Targeting G-quadruplexes in gene promoters: a novel anticancer strategy. Nat. Rev. Drug Discov. 10, 261-275.

20. Kotas, M. E., and Medzhitov, R. (2015). Cell 160, 816-827.

21. Richter, C.P. (1943). Total self-regulatory functions in animals and hman beings. Harvey Lecture Series 38, 63-103.

\section{Comment on this article:}

\section{(f) $(8)$ in $8+\boldsymbol{S} P$}

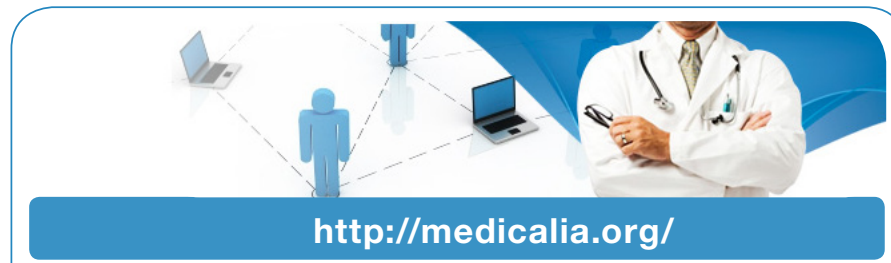

Where Doctors exchange clinical experiences, review their cases and share clinical knowledge. You can also access lots of medical publications for free. Join Now!

\section{Publish with iMedPub}

http://www.imed.pub

International Archives of Medicine is an open access journal publishing articles encompassing all aspects of medical science and clinical practice. IAM is considered a megajournal with independent sections on all areas of medicine. IAM is a really international journal with authors and board members from all around the world. The journal is widely indexed and classified Q1 in category Medicine. 